\title{
Translation in Maharashtra: An Overview of the Past Two Hundred Years
}

\author{
PRITHVIRAJSINGH THAKUR
}

There is a rich and old tradition of translation in India. The advent of the British and the establishment of the British rule in India is an important epoch in the history of translation in India. Indian translation has been enriched by the translations done by several translators from English into Indian languages and viceversa. This paper aims to look the tradition of translation in Maharashtra in the last two hundred years. There is a special significance this period because it is in this age that the activity of translation in Maharashtra took a new turn.

Keywords: translation, Indian languages, Marathi, Maharashtra.

\section{Introduction}

It is only natural and obvious that a linguistically and culturally rich and diverse country like India should have a glorious and rich tradition of translation along with its equally rich body of creative literature .Like other parts of India, Maharashtra has also made quite a rich and illustrious contribution to the field of translation in India. In this paper, I propose to look at the history of translation in Maharashtra and the contribution of the scholars of Maharashtra to the field of Indian translation in the $19^{\text {th }}$ and the $20^{\text {th }}$ century. I will begin by discussing the translations from English into Marathi and then proceed to discuss translation from Marathi into English. Translations of the Shakespeare's works from English into Marathi is so rich that a separate section has been devoted to its discussion.

\section{English-Marathi Translations: An Overview}

Like other Indian languages, Marathi also has an illustrious history of translation. It begins with Sant Dnyaneshwar's Bhawarthdeepika or Dnyaneshwari, which is a verse rendering of the Bhagavad Gita with Dnyaneshwar's commentary (also in verse). This is followed by the works of poets like Narendra, Mukteshwar, Moropant, Shridhar, Vaman Pandit and Raghunath Pandit who rendered various Sanskrit texts like the epics Ramayana and Mahabharata (or episodes from them), or tales from the Puranas in glorious Marathi verse. However, the tradition of translation from other languages into Marathi grew into a literary polysystem in the colonial period after the decline of the Maratha power and coming of the British rule. The old order was crumbling giving place to new. Everything was changing and literature and culture were changing all the more rapidly. A new class of 
English educated youth was bringing about a renaissance of ideas. Pandit (2017:136) tells us:

The socio-cultural ethos in the then contemporary Maharashtra represented a renaissance of ideas caused by the colonial contact and confrontation which led to the emergence of a translation and literary culture which was completely different from the past.

A new culture of translation emerged in the nineteenth century which was quite different from the hitherto dominant culture of translation in Marathi. Translation was seen by the rulers as the means of transferring the thoughts, ideas and value system of the dominant (read English) culture into the language and culture of Maharashtra. The British rulers recognized the importance of translators as the agents of cultural change and used them to the fullest extent. Pandit (2017) divides the growth of translation culture in Marathi into three broad phases: from 1825 to 1850,1850 to 1875 and 1875 to 1900.

In the first phase, mostly the English textbooks were translated into Marathi with an intention of making the natives familiar with European knowledge. This was followed by the translation of books on moral education which included translations of books like Aesop's Fables, Children's Friend by Berquin (translated as Balmitra by Sadashiv Kashinath Chhatre) and Pilgrim's Progress (translated by Hari Keshavji). These books became very popular with the school children and the general public also. On another front, Balshastri Jambhekar, the founder editor of the first Marathi newspaper Darpan (1832), was giving Marathi translations of English news items in his newspaper.

Translation of English works into Marathi got a new impetus with the establishment of the Bombay University in 1857. Before that, scholars like Major Candy (who brought out a list of Hints for the Guidance of Translators in 1850) had been making significant contribution to enrich the tradition of translation in Marathi. The British government established the Dakshina Prize Committee in 1851 to reward good translations and independent writings. All this gave a great boost to the activity of translation which is evident from both the number and quality of the works translated from English into Marathi in this period (i.e. from 1850-1875). There started a great fashion of translating Shakespeare's plays in Marathi. It has been discussed in detail in the next subsection in this chapter. Apart from Shakespeare's plays, other English literary and scholarly works were also translated into English. For instance, Krishnashastri Chiplunkar translated Dr. Johnson's novel Rasselas as well as Mill's Political Economy into Marathi.

After 1875, Marathi translations of English texts grew both in number and variety. Raosaheb Viswanath Narayan Mandlik translated Mountstuart Elphinstone's History of India as Hindustānschā Itihās in 1891. Marathi translations of Shakespeare's plays continued to appear. Other English works like Goldsmith's Good-Natured Man and She Stoops to Conquer, Daniel 
Defoe's Robinson Crusoe appeared in Marathi translation in this period. The great Marathi historian Vishwanath Kashinath Rajwade made a huge contribution to the cause of translation in Maharashtra by founding a journal called Bhasshantar in 1895. This journal was devoted entirely to the publication of great English scholarly works in Marathi translation. In this journal, Rajwade published his Marathi translations of works like Plato's Dialogues and Gibbon's Decline and Fall of Roman Empire. Another great work of western literature that was translated into Marathi in the late nineteenth century was Homer's Iliad. Ganesh Ramkrushna Hawaldar did a verse translation of Iliad in Marathi about this time. It was published in 1913. It still remains the only verse translation of Iliad in Marathi and most probably in any Indian language.

Nineteenth century was thus a golden age of translation in Marathi scholarship and it fostered a tremendous change in the history of Marathi literature. It was in this age, that Marathi prose was reborn in a new form. In the words of Maya Pandit:

Thus, the study of translation culture in the nineteenth-century Maharashtra reveals a marked development in the translation culture. Choice of books for translation, strategies adopted for translation, actual functions of translations in the literary polysystem underwent a lot of changes because they were defined by the colonial discourse. The field of translations underwent several changes which were a result of the changing nature of the relationship between the natives and the colonial rulers. Yet it cannot be denied that translations played a major part in shaping modern Marathi prose (Pandit 2017:155-156).

\section{Shakespeare in Marathi Translation}

After the start of English education in Maharashtra with the establishment of the Bombay University in 1857, there soon appeared a generation of young English educated Maharashtriyans. They were fascinated by the British literature and particularly by Shakespeare. The Marathi people had always been the lovers of drama. The plays of Shakespeare opened a treasure-trove of great dramatic art before them. They soon took to translating/adapting Shakespeare into Marathi with the intention of enriching Marathi literature and popularizing Marathi theatre even more. Thus, the tradition of the translation of Shakespeare's plays into Marathi started. This tradition is so long, so rich and so full of variety that any discussion of the tradition of Marathi-English translation cannot be complete without taking into account the translation of Shakespeare into Marathi.

The tradition of translating/adapting Shakespeare's plays into Marathi is very long and illustrious. It begins in 1857 with Nanasaheb Peshwa and continues till date. 
Though the early Marathi dramas were mostly the adaptations/translations of classical Sanskrit plays of Kalidas, Bhas and Bhavabhuti, there had come into existence in the late $19^{\text {th }}$ century Maharashtra, a branch of plays translated from English called 'the bookish plays', 'Bookish' was the term used for the Marathi plays translated from Shakespeare .However, translation of Shakespeare's plays into Marathi had started even before 1860s .Nana Saheb Peshwa translated Hamlet in 1857. But it was after 1860, that Shakespeare was translated into Marathi more seriously and with more zeal. A number of translations started to appear. Prominent among them were Othello) 1867 (by Mahadevshastri Kolhatkar, Vilakshan Nyaya Chaturya) 1868 (by Sakharam Pandit and Stri Nyaya Chaturya by A.V. Patkar] both translations of The Merchant of Venice, [Vijaysingh] Julius Caesar [(1872) by K.G .Natu, Tempest) 1875 (by Nilkanth Janardan Kirtane, Bhranikrut Chmatkar- Comedy of Errors),1878 (by B. R. Pradhan and S. B. Jathar and Tara-Cymbeline by Vishnu Moreshwar Mahajani (1877). These plays became popular immediately -particularly among the English educated people of Mumbai.

From 1880 onwards, we see a significant improvement in the number and quality of the Marathi translations of Shakespeare's plays. S. M. Ranade's translation of King Lear -Atipid Charita appeared in 1880. Due to the demands of his audience, he had to change the ending of the play to a pleasant and happy one. Vikaravilasita, Gopal Ganesh Agarkar's famous translation of Hamlet, appeared in 1883 and remained popular for a long time .In fact, it is still read and studied .Vitthal Seetaram Gurjar )1905 (and later Mohan Agashe brought Merchant of Venice as a musical play with the titles Sangeet Pranaymudra and Sangeet Saudagar respectively. Though Hamlet and the Merchant of Venice remain the most translated of Shakespeare's plays in Marathi, translations of other plays of Shakespeare also appeared after 1880. Notable among them were -Tratika (Taming of the Shrew) and Veermani va Shringarsundari (Anthony and Cleopatra) by V.V. Kelkar as well as Mohavilasita (Winter's Tale) and Vallabhanunaya (All's Well that Ends Well) in 1887 by Vishnu Moreshwar Mahajani.

Among other notable translations and adaptation, there are plays like Bhural athava Ishawikrit Lapandaav [A Comedy of Errors] (1876) by A.V. Patkar, Prataprao ani Manjula [Antony and Cleopatra] by A.V. Musale (1882) and Zunjarrao [Othello] (1890) by G .B. Deval G. S. More and L.N. Joshi translated King Lear as Kanyaparikshan and Vikaar-Vihaar respectively in 1881 .

Shakespeare's English history plays were also brought into Marathi but they did not enjoy as much success as his other plays. Among the English history plays, L.N. Joshi brought King John as Kapidhwaj into Marathi in 1904 while Hanmant Atre translated King Henry VIII as Raja Ragunathrao in the same year. King Henry V and King Henry IV were translated as Pancham Henry Charit (1911) and Bandache Praayashchitta (1915) by Khanderao Belsare and Narayan Limaye respectively. Then there were three adaptations 
of the Tragedy of King Richard III as Jayajirao (1891) by B. R. Nanal, Daiva Durvilasa (1904) by Vasudeo Sathe and Raja Rakshas? (Unknown) by K. H. Dikshit.

All these early Marathi translators of Shakespeare had to deal with more or less the same problems that the translators of Shakespeare in other Indian languages faced. They all faced the problem of adapting a foreign dramatic form to suit the Indian situation. According to Bharat's Natyashastra, tragedy was something totally forbidden on Indian stage and many times we see the translators ending the play happily. They struggled to find a suitable equivalent of Shrew for example and we see Kelkar using the Tratika -the female demon from Ramayana -as an equivalent of Shrew. Sisir Kumar Das in his essay Shakespeare in Indian Languages in Trivedi and Bartholomeusz) 2005 (gives us a detailed account of the problems faced by Indian translators of Shakespeare - particularly in the $19^{\text {th }}$ century when the society was more orthodox and things like premarital love could not be discussed even privately -let alone in public. Das tells us how D. A. Kesakar's Marathi translation of Romeo and Juliet -Tara Vilas (1908) -faced stiff resistance and could not be staged at all. But at the same time, another translation Mohan Tara by K. R. Chapkhane became extremely popular. Another important adaptation of The Merchant of Venice is Ek Pound Maas (A Pound of Flesh) by S. B. Gondhalkar which appeared in 1944.

After 1950, we see in Marathi theatre, a considerable revival of interest in Shakespeare. Many stalwarts of Marathi literature/theatre came up with translations /adaptations of Shakespeare with more skill and maturity than ever. The great Marathi poet and dramatist Vishnu Vaman Shirwadkar alias Kusumagraj, came up with Rajmukut [Macbeth] and Othello between 1954 to 1960. Shirwadkar's engagement with Shakespeare does not stop here. In his famous Marathi drama Natsamrat [The Great Actor], we have an extremely wonderful and soul stirring translation of 'to be or not to be' as Jagawa ki Maraava haa ekach prashan aahe (To be or not to be, that is the question). This particular soliloquy in Natsamrat still holds a special place in the hearts of the lovers of Marathi literature and can very well be termed as an excellent example of transcreation. Shirwadkar has described his tryst with Shakespeare in Shodh Shakespearecha [In Search of Shakespeare] -a collection of articles written on Shakespeare (2012).

Nana Jog, a stalwart in the field of modern Marathi theatre translated Hamlet in 1959. This is considered to be a much acclaimed and famous translation and is often compared with Agarkar's Vikaravilasita .Another great Marathi poet, G.V. Alias Vinda Karandikar, also a professor of English, translated King Lear as Raja Lear in 1974.

In this tradition, the most recent Marathi poet to translate Shakespeare is the legendary poet Mangesh Padgaonkar who translated The Tempest as Waadal in 2001, Julius Caesar in 2002 and Romeo and Juliet as Romeo ani Juliet in 2003 .Arun Naik is another famous contemporary translator and producer of Shakespeare's plays .He has translated and produced Hamlet, 234 
Macbeth and Othello .In addition to this, he has also translated Shirwadkar's book Shodh Shakespearecha into English as 'In Search of Shakespeare (2012)' .

It is important to add here, that almost all these modern translations of Shakespeare have detailed introduction, notes and appendices thereby making a significant contribution to Shakespeare criticism in Marathi. Mumbai based Avishkar Theatre Group staged 'Jungle me Mangal', adaptation of $A$ Midsummer Night's Dream in the form of Marathi folk drama called tamasha in February 2007.

\section{Translations from Marathi to English}

It is difficult to trace the beginning of the tradition of translation from Marathi into English with certainty. Marathi started coming into close and frequent contact with English in the late eighteenth and early nineteenth century. During this period however, the focus of the English scholars was mainly on translating texts from Sanskrit into English. The earliest and arguably the most significant result of Marathi-English contact was the Marathi-English dictionary of Captain James Thomas Molesworth and Major Thomas Candy which is still in print after it was first published in 1831.

Sawant (2005) traces the beginning of translation from Marathi into English back to the early twentieth century. He calls the American missionary Justin E. Abbot, the pioneer of the tradition of translation from Marathi into English. Abbot translated the poetry of almost all the Marathi saints into English publishing his translations in the form of eleven books under the series The Poet-Saints of Maharashtra. In this series, he published the following books:

Bhanudas (1926), Eknath (1927), Bhikshugeet Athva Anutaptakadarya (1927), Dasopant Digambar (1927), Bahinabai (1929), Stotramala (1929), Tukaram (1930), Ramdas (1932) Stories of Indian Saints, Vol I (1933), Stories of Indian Saints, Vol. II (1934), and Nectar from Indian Saints (1935).

Sawant honours the contribution of Abbot to the cause of translation from Marathi into English in the following words:

"Justine Abbot became almost an insider to Marathi culture and tried to absorb the best in the medieval 'saint poetry' tradition of Maharashtra. (Sawant, 2002: 31-32) Abbot's lifelong translation work of Marathi saint-poets thus marked a significant shift in the cultural and literary contact between the West and Maharashtra. The tradition of translating from Marathi into English continued when some of our own bilingual authors began to render Modern Marathi literature in English" (Sawant, 2005:250). 
After the 1950s, we find a quite significant surge in the translation from Marathi into English. Most of these were the translations of Marathi short stories, novels, drama and poetry.

Ian Raeside, Lecturer in Marathi and Gujrati of the School of Oriental and African Studies (SOAS), University of London translated a collection of modern Marathi short stories written by Gangadhar Gadgil, Arvind Gokhale, P. B. Bhave, Vyankatech Madgulkar, D. B. Mokashi, D. M. Mirasdar, Malatibai Bedekar and others as The Rough and the Smooth in 1966.

$\mathrm{He}$ was also commissioned by the UNESCO to translate S. N .Pendse's novel Garambicha Bapu which he translated as Wild Bapu of Garambi in 1969.

Shuba Slee's translated Kiran Nagarkar's novel Saat Sakkam Trechalis as Seven Sixes are Forty-three. It was published in 1980 by the University of Queensland Press, St. Lucia, Queensland, Australia. Kumud Mehta has translated P. S. Rege's Marathi works Savitri and Avalokita into English in 1969.

Recently, quite a lot of significant Marathi texts have been translated into English .Dilip Chitre and Bhalchandra Nemade are two famous names in this area. Dilip Chitre translated poems of Saint Tukaram into English as Says Tuka.

Marathi drama is now being translated with a lot of zeal into English. Although, till the 1990s, very few Marathi dramas had been translated in to English.

Jayant Karve and Elinor Zoliet have translated Vijay Tendulkar's play Ghashiram Kotwal into English in 1984 .Six of Tendulkar's plays have been translated into English so far. Among them is the English translation of Sakharam Binder (1973) by Shanta Shahane and Kumud Mehta. Priya Adarkar translated Shantanta, Kort Chalu Ahe as Silence, the Court is in Session in 1979. After 1990, a number of Marathi dramas began to appear in English translation. Priya Adarkar's English translation of five plays of Vijay Tendulkar was published by Oxford University Press in 1992. Today, many contemporary Marathi plays by writers like G. P. Deshpande, Satish Alekar, Shanta Ghokale, and Mahesh Elkunchwar have been translated into English with a lot of critical acclaim.

Prof. Datta Bhagat's drama Vaataa Palwaataa has been translated into English as 'Routes and Escape Routes (2001)' Gauri Deshande has translated Satish Alekar's play Mahanirvan as 'Mahanirvan -The Dread Departure (1989)' G. P. Deshpande's play Chanakya Vishnugupta has also been translated into English in 1996 by Maya Pandit .

Many important Marathi works of fiction have also appeared in English recently. They have been quite well received both by the English reading public and the critics. Jerry Pinto has translated Daya Pawar's novel Baluta into English in 2015. Sudhakar Marathe has translated Bhalchandra Nemade's novel Kosla as 'Cucoon (1997)' and R. R. Borade's novel Pachola as 'Fall (1999)'. Marathe has also translated Ulgulaan- a collection of Marathi poems 
by Dalit poet Bhujang Meshram. Dalit poet Arjun Dangle has published a collection of English translation of selected poems of a few Marathi Dalit poets as 'Poisoned Bread: Translations from Modern Marathi Dalit Literature (2009)'. Jaysingh Rao Pawar's biography of Shahu Maharaj has been translated into English. Arun Sadhu's novel Viplav has been translated into English along with some of his short stories. Vishwas Patil's novel Sambhaji has also appeared in English in 2007.

Thus, it is quite obvious from this discussion, that the tradition of translation in Maharashtra is flourishing and has come a long way now. The empire is writing back powerfully and a great many Marathi works including the works of Dalit, Adivasi and other underprivileged writers- are being translated into English. This will undoubtedly help Marathi literature acquire global readership and give a voice to the marginalized who had been side-lined so far.

\section{References}

ASADUDDIN, M. 2006. Translaion and Indian Literature: Some Reflections. Translation Today 3.1-2.1-20.

ChAOUdHURI, INDRA NATH. 201. "Towards an Indian Theory of Translation". Indian Literature 54.5. (259) -113-123.

DAS, SISIR KUMAR. 2005. Shakespeare in Indian Languages. India's Shakespeare, ed. by Poonam Trivedi and Dennis Bartholomeusz, 42-65. New Delhi: Pearson.

EngBlOM, PHILIP. 1982. Marathi Poetry in English Translation. Journal of South Asian Literature, 17.1.115-132.

GuPTA, NEENA. (ed.) 2016. Translating Bharat, Reading India. New Delhi: Yatra.

MUKHERJEe, MEENAKSHI. 1972. Indian Novels in Translation. Indian Literature, 15.3.7-65.

NARKAR, MAYA. 1990 A Linguistic Study of the Nineteenth Century Marathi Translators. Kolhapur: Shivaji University Dissertation.

PANDIT, BABAJI MAHARAJ. (ed.) 1997. Dnyaneshwari Goodharthdipika. Gorakhpur: Gita Press.

PANDIT, MAYA. 2017. History of Translation Culture in Nineteenth Century Maharashtra: An Exercise in Colonial Cultural Politics. In Tariq Khan (ed.), History of Translation in India. 135-159. Mysuru: National Translation Mission, CIIL.

RAJADHYAKSHA, M. V. 1964. Shakespeare in Marathi. Indian Literature, 7(1). 83-94.

Verghese, C. PAUl. 1969. Problems of the Indian Translator in Englis. Indian Literature, 12.1. 86-93. 